\title{
El imaginario social de la mujer venenosa: ciencia, metáfora y hermenéutica
}

\author{
Carmen FERNÁNDEZ TIJERO \\ Juan R. COCA \\ Universidad de Valladolid \\ tijero@fyl.uva.es \\ juancoca@soc.uva.es \\ Eulalia PÉREZ SEDEÑO \\ Consejo Superior de Investigaciones Científicas \\ eulalia.psedeno@cchs.csic.es
}

Recibido: Enero 2016

Aceptado: Noviembre 2016

\section{RESUMEN}

Son muchas las supersticiones que rodean al ámbito de lo femenino, y que hacen de la mujer el elemento constitutivo esencial de una amplia variedad de imaginarios sociales. Este trabajo presenta el análisis de uno de esos aspectos: el papel de la naturaleza femenina como poseedor de un veneno de efectos nocivos para su entorno, el flujo menstrual, que convierte a toda mujer en una potente hechicera por naturaleza, en un ser dominado por la irracionalidad, frente al espíritu objetivo y científico del hombre y, por tanto, inferior. Esta idea aparece en los primeros tratados médicos de la Antigüedad clásica, perdurando incluso en las obras científicas de auctoritates del mundo de la medicina hasta el Renacimiento y en libros de texto médicos actuales.

Palabras clave: Ciencia, hermenéutica, historia, imaginario social, medicina, menstruación, veneno, metáforas.

Social imaginary of the poisonous women: Science, metaphore and hermeneutic

\begin{abstract}
They exist so many superstitions involving the feminine sphere, which set the feminine up as the heart of a wide variety of collective imaginaries. This article analyzes one of those myths: the female that owns a poison with damaging efects on the environment, that is the menstrual flow. It makes every woman into a powerful wizard by nature, a being commanded by irrationality opposite to the objective and scientific spirit, which is distinctive of men. We can found this idea in some medical texts, from the very first "scientific" text in the Classical
\end{abstract}


Antiquity, enduring even in the scientific works by the medical auctoritates up to the Renaissance and in current medical textbooks.

Keywords: Science, hermeneneutic, history, social imaginary, medicine, menstruation, poison, metaphors.

\section{INTRODUCCIÓN}

Los mitos, las leyendas y los imaginarios sociales que rodean la idea de la mujer venenosa son numerosos. Desde una perspectiva histórica acaban convirtiéndola en la hechicera por excelencia de todas las civilizaciones antiguas. Esta consideración un tanto sobrenatural de la mujer tuvo una fuerte influencia en el papel relegado que ocupó ésta en dichas sociedades. Por una parte, es conocida su faceta de envenenadora, puesto que es la mujer la mejor conocedora de las plantas y remedios medicinales desde la prehistoria, ya que era ella la encargada de las tareas de cultivo y recolección (Bernis y Cámara, 1982; Iglesias, 2003; Fernández Tijero, 2009). Estas facetas esotéricas de la mujer han sido apoyadas por los autores de obras científicas o pseudocientíficas del campo de la medicina y la filosofía en un intento por buscar una explicación racional a tales hechos. Por otra parte, la fisiología del cuerpo femenino incita además creencias y supersticiones que se elevan al rango de hechos reales, llegando incluso a servir de base a procedimientos terapéuticos, que en definitiva no son más que un mero fruto del desconocimiento de los procesos fisiológicos del sexo femenino.

A juicio de los autores del presente texto debemos ser conscientes de que estas características de la fisiología femenina han sido la herramienta de justificación idónea para que se le haya asignado, a la mujer, roles asociados - de un modo u otro- a la esfera privada y del cuidado, así como relativo al sentimiento. Esto ha arraigado en distintos tipos de estereotipos sexuales.

A los varones, comúnmente, se les han asociado cualidades tales como las de racionalidad, dominación, independencia, frialdad y objetividad. En cambio, las mujeres se asociaron con la irracionalidad, pasividad, dependencia, ternura, emotividad y subjetividad. Se considera que estas características «femeninas», opuestas a las «masculinas» y minusvaloradas, son un obstáculo para la prosecución de una carrera científica, ya que las cualidades necesarias para hacer ciencia son las «masculinas» (Pérez-Sedeño, 2008). De ahí que la idea de la mujer con poderes mágicos, que podría haber sido positiva, ha devenido en la transmisión de un imaginario social de la mujer negativo y alejado del conocimiento científico. Esta visión se ha mantenido con fuerza hasta hace poco tiempo siendo numerosos los ejemplos estudiados en el siglo XX. En la actualidad parece que la situación está cambiando, aunque todavía conservamos mucho de estos mitos, leyendas e imaginarios.

El objetivo general de este trabajo es analizar la incidencia de factores sociológicos y credenciales sobre la visión femenina actual. Para ello buscaremos, en principio, las raíces de estas creencias en el campo de la filosofía natural. Posteriormente analizaremos algunos textos científicos greco-romanos, relativos al campo de la fisiología o filosofía natural, que muestran cómo se ha ido construyendo 
parte de este complejo y multidimensional imaginario social en el ámbito científico. En muchas ocasiones recurriremos a los textos médicos de los autores medievales, en calidad de transmisores y recopiladores de este imaginario originado en la ciencia antigua, que nos aportan testimonios de las fuentes primarias. Por último, mostraremos el correlato que ello tiene en ciertos aspectos de la realidad social actual.

Antes de continuar, es necesario recordar que al hablar de lo imaginario viene a nuestra mente palabras tales como idealización, imaginación, ensoñación, etc. Lo imaginario mantiene una estrecha relación con la imagen, la imaginación y con la aprehensión primera que, a su vez, se vinculan con la realidad, en vista de que ambas constituyen demarcaciones desde la enorme cantidad de posibilidades de la realidad y los numerosos modos de aprehenderla (Simmel, 2000). Además, lo imaginario también funciona como elemento de cohesión social. De hecho, la cohesión social reposa en una matriz más imaginaria que propiamente real (Carretero, 2011). Esto se convierte en elemento fundamental de todo vínculo colectivo. Ello es debido a que los imaginarios sociales solidifican un sentido de realidad, asegurando la repetición de las mismas formas que regulan la vida en sociedad. Estas matrices de sentido que existen en nuestras mentes, se inscriben dentro de la sociedad como sistema de interpretación del mundo. De allí la necesidad de estudiar la producción social de sentido, tal y como pretendemos hacer en el presente trabajo.

Nuestra intención es, por tanto, conocer los imaginarios sociales existentes en aquella época sobre la mujer y, concretamente, sobre su genitalidad y ver cómo siguen influyendo en la actualidad. La estructura del trabajo la hemos focalizado en los elementos ficcionales que condicionaron los imaginarios sociales de la feminidad (sobre todo centrada en la sexualidad). Somos conscientes que este artículo se adentra en una problemática muy compleja, con muchas aristas. De ahí que se pueda considerar que faltan perspectivas de análisis. Partimos, entonces, del sesgo epistemológico proveniente de las áreas de conocimiento de los autores del texto. Esperamos que el lector sepa comprender este aspecto.

Por último, también queremos resaltar que los resultados aportados ayudan a comprender, desde un estudio filológico-histórico, una serie de estructuras de significación social. Pero todo trabajo social no puede ser conclusivo. Menos aún si hablamos de un trabajo hermenéutico en el que se asume la existencia del círculo hermenéutico que implica una revisión constante de la información y de las significaciones sociales en función de los contextos socio-históricos de análisis.

\section{METODOLOGÍA}

En el presente trabajo se ha realizado una investigación cualitativa. Para ello se ha realizado un proceso de triangulación consistente en un análisis filológico-histórico de los textos ginecológicos medievales (aunque también se ha hecho mención de textos greco-latinos) que, a nuestro juicio, han tenido más impacto en aquel momento: Hipócrates, Aecio de Emida, Sorano, Avicena, Anglico, Guainerio, etc. Los textos médicos medievales aúnan la ciencia de la Antigüedad (fundamentalmente aquella referida al marco judeo-cristiano) con la prestigiosa medicina árabe y judía; además de 
ser la base de la explosión científica del Renacimiento.

A partir de ahí hemos realizado una aproximación socio-hermenéutica a dichos textos, basándonos en lo expuesto por Juan R. Coca (2010) para, así, poder comprender mejor los imaginarios que se han ido produciendo sobre la mujer y su realidad ontológica. Por lo tanto, y en suma, hemos realizado un análisis socio-hermenéutico de los imaginarios sociales existentes en los textos históricos a los que hemos hecho mención.

La metodología de los imaginarios sociales ya está bien establecida. En los últimos años se han desarrollado un gran número de trabajos al respecto que han logrado consolidar y estandarizar dicha propuesta metodológica (Baeza, 2008; Coca, 2015; Girola, 2012; Pintos, 2014, entre muchos otros). Por ello, y por cuestiones de espacio, consideramos que no es necesario detallar esta metodología. Lo que sí queremos dejar claro es que al hablar de imaginarios sociales no estamos haciendo mención de simples ideaciones. El concepto de imaginario social tiene un claro componente social y hace referencia a las construcciones que se institucionalizan a través de procesos sociales comunicativos.

\section{RESULTADOS}

\subsection{ANÁLISIS HISTÓRICO-FILOLÓGICO}

\section{- Menstrum}

Entre los muchos elementos ficcionales que rodean a la mujer se distingue, de una manera especial como parte del magma de significación (Castoriadis, 1983) imaginario, todo lo relacionado con el fenómeno de la menstruación. El ciclo menstrual no siempre ha sido considerado, como lo es en la actualidad, un proceso fisiológico natural que capacita a la mujer para la procreación, sino más bien al contrario. Tradicionalmente se ha considerado la sangre menstrual como una sustancia tóxica, lo cual, durante mucho tiempo, ha tenido sus consecuencias en la actitud de la sociedad hacia las mujeres (Bildhauer, 2005).

Algo tan natural como puede ser el apetito sexual, en la mujer se considera maléfico y con poder hechicero hacia el hombre, víctima de los deseos irrefrenables e, incluso, innatural. La vagina es concebida como un ser hambriento que, sobre todo durante el ciclo de la menstruación, quiere devorar el pene y los testículos del hombre, tiene ansia de su flujo vital, su semen, que extrae succionando su miembro durante el acto sexual (Bildhauer, 2005 y Elliot, 1999). Lo que servirá como objeto de burla en algunas comedias (Canet, 1996). Por tanto, todo parece indicar que el proceso imaginario fantástico relativo a la vagina nos muestra un doble código en el que los aspectos relativos a la fecundidad y al sexo son oscurecidos tras una visión coercitiva de la vagina como una estructura destructiva y devoradora. Además, se le atribuye a la menstruación todo tipo de propiedades, por lo general negativas, nocivas y venenosas. Plinio, a este respecto, señala lo siguiente: 
"Pero no encontraremos difícilmente nada más prodigioso que el flujo menstrual. La proximidad de una mujer en este estado hace agriar el mosto; a su contacto, los cereales se convierten en estériles, los injertos mueren, las plantas de los jardines se secan, los frutos de los árboles donde ella está sentada caen; el resplandor de los espejos se enturbia nada más que por su mirada; el filo del acero se debilita, el brillo del marfil desaparece, los enjambres de las abejas mueren; incluso el bronce y el hierro se oxidan inmediatamente y el bronce toma un olor espantoso; en fin, la rabia le entra a los perros que prueban de dicho líquido y su mordedura inocula un veneno sin remedio. Hay más: el asfalto, esa sustancia tenaz y viscosa que, a una época precisa del año sobrenada un lago de Judea, que se llama Asphaltites, no se deja dividir por nada, pues se adhiere a todo lo que toca, excepto por un hilo infectado por este veneno. Se dice incluso que las hormigas, esos animalejos minúsculos, le son sensibles: ellas echan los granos que transportan y no los vuelven a recoger. Este flujo tan curioso y tan pernicioso aparece todos los treinta días en la mujer, y, con más intensidad todos los tres meses (Canet, 1996: 22)”.

La concepción asombrosa y desnaturalizada de este proceso fisiológico viene apoyada por el influjo de las fases lunares, eclipses, y demás fenómenos celestes que influyen sobre el cuerpo femenino (Plinio, 2002). Pues bien, casi todos los tratados ginecológicos analizados coinciden en dicho punto: el ciclo de la menstruación se rige por las fases lunares. Sólo Sorano de Éfeso, médico romano del siglo II d.C., en su Ginecología, obra en la que critica muchas ideas tradicionales, rechaza la idea de que la menstruación está gobernada por la luna:

“Algunas mujeres menstrúan un día, otras dos, otras incluso una semana o más. Esto ocurre todos los meses, pero no con precisión en todos los casos, sino hablando de forma general, pues a veces se adelanta o retrasa varios días. En cada mujer se produce en un momento dado, característico de ella y no [se da] en todas las mujeres en el mismo [periodo] como [decía] Diocles, ni, como dijo Empédocles, cuando la luz de la luna está menguando. Algunas mujeres menstrúan antes del vigésimo día del mes, otras en el vigésimo y también otras mujeres menstrúan cuando la luz de la luna está creciente, algunas cuando está menguando y el resto menstrúa en en días tales como es habitual en ellas” (Lloyd, 1983: $170-171)$

Sin embargo, estas ideas no acabaron siendo asumidas por el imaginario colectivo de la época y se mantuvo el pensamiento supersticioso en las explicaciones de la menstruación femenina.

El imaginario social occidental relativo a esta concepción nociva del flujo menstrual tiene una doble raíz socio-histórica: el mundo greco-latino y el sistema de pensamiento judeocristiano (Durand, 1981). En ambos marcos de significación religiosa está presente esta idea del ciclo menstrual como algo con poder sobrenatural. De hecho, en el Levítico leemos (NBE, 1984):

"Yahvé habló a Moisés, diciendo: "Habla a los hijos de Israel y diles: Cuando dé a luz una mujer y tenga un hijo, será impura durante siete días; será impura como en el tiempo de su menstruación. Al octavo día será circuncidado el hijo, pero ella 
quedará en casa durante treinta y tres días en la sangre de su purificación; no tocará nada santo ni irá al santuario hasta que se cumplan los días de su purificación. Si da a luz una hija, será impura durante dos semanas, como el tiempo de su menstruación, y se quedará en casa durante sesenta y seis días en la sangre de su purificación” (Levítico 12, 1-5).

Y con respecto a la menstruación:

"Cuando la mujer tuviere flujo de sangre, y su flujo fuere en su cuerpo, siete días estará apartada; y cualquiera que la tocare será inmundo hasta la noche. Todo aquello sobre que ella se acostare mientras estuviere separada, será inmundo; también todo aquello sobre que se sentare será inmundo. Y cualquiera que tocare su cama, lavará sus vestidos, y después de lavarse con agua, será inmundo hasta la noche. También cualquiera que tocare cualquier mueble sobre que ella se hubiere sentado, lavará sus vestidos; se lavará luego a sí mismo con agua, y será inmundo hasta la noche” (Levítico 15, 19-22).

Como sabemos, el Levítico es un conjunto de textos en los que se basará el Cristianismo para defender la extendida idea de la maldad innata de la mujer. Así pues, esta creencia no sólo revirtió en el papel secundario de la mujer en las sociedades antiguas, sino que además fue uno de los pilares de los tratados cristianos sobre la miseria humana, iniciados por el De contemptu mundi sive de miseria conditionis humanae, de Innocencio III.

\section{- Vapores nocivos}

La raíz de esta consideración mágica de la sangre menstrual arranca de la comparación de la fisiología humoral del hombre con la de la mujer. Según Aristóteles, el calor es el principio fundamental y de perfección: "Lo que por naturaleza tiene menor proporción de calor es más débil”. La mujer es más fría que el hombre y, por tanto, menos perfecta. El semen y los menses, o fluido menstrual, son análogos entre sí. Ambos son residuos de nutrición útil. Aristóteles había observado que las sustancias se transforman por el calor y de ahí afirmaba que el calor 'cuece' la sangre y la convierte en semen. La menstruación es mayor y más parecida a la sangre que el semen, señal de la menstruación está menos cocida, lo que es normal en un sexo más frío y más débil que es menos capaz de cocer el residuo útil (Aristóteles, 2010).

Las fuentes filosóficas y científicas estudiadas atestiguan dos emisiones diferenciadas producidas por las mujeres: por un lado el esperma, que se producía de la misma manera que en los hombres y acarreaba las mismas consecuencias en su retención, y por otro, la sangre menstrual como residuo, que por el defecto físico de la mujer no llega a transformar por cocción en esperma a causa de su falta de calor, y que en la época del embarazo sirve para la alimentación del feto, transformándose en leche una vez nacido el niño (Aristóteles, 2010 y Canet, 1996).

Estos datos nos muestran, podríamos decirlo así, que la mujer era vista como un varón imperfecto (Cappai, 1993 y Gourevitch, 1984), que a causa de su frialdad no puede elaborar la materia procedente del alimento ingerido, que se corrompe y da lugar 
a vapores infectos o humores corrompidos (Livi, 1984). Dichos humores, si no son eliminados a su debido tiempo, terminan produciendo el envenenamiento de todo el cuerpo. Esta concepción produce una condena 'natural' de la mujer. El macho, en cambio, tiene calor en alto grado, es capaz de cocer la materia y eso destruiría el feto. Sólo un ser incapaz de cocer toda la materia puede nutrir el feto. La imperfección de la mujer es necesaria para perpetuar la raza, por tanto, es natural.

Esta concepción imaginaria de la mujer como una especie de varón imperfecta se ha mantenido hasta la actualidad tal y como nos indican los procesos de masculinización de aquellas mujeres que ostentan un cargo público en la actualidad (Camacho, 2001; Cazarín, 2012; París-Huesca, 2013, entre otros).

Estas creencias acerca de la naturaleza femenina proporcionan el fundamento médico-científico para la desconsideración social de la mujer y, además, es el germen androcéntrico del posterior discurso científico. El fundamento filosófico lo encontramos ya en Platón (1992). Al tratar el tema de la reencarnación, el filósofo explica que un individuo se reencarna en sexo femenino cuando su vida ha transcurrido en el exceso y la falta de moderación, haciendo el mal, por lo tanto, la mujer es automáticamente una degeneración del hombre. Siguiendo en el ámbito de la filosofía natural, y acercándonos de nuevo al campo de la medicina, Aristóteles y Plinio explican las causas naturales, de la constitución fisiológica de la mujer, que corroboran su inferioridad, basándose ya no sólo en costumbres, modo de vida o virtudes, sino en características morfológicas, fisiológicas y psicológicas que se producen también en una amplia gama de especies animales.

Aristóteles también explica características físicas y psicológicas en términos de las diferencias de sangre, incluyendo la fuerza, la inteligencia y carácter. En De Partibus Animalium, identifica las principales diferencias de la sangre como que sea expresa o clara, pura, fría o caliente y que esas diferencias sirven a buenos propósitos. Cuanto más espesa y caliente sea la sangre, más contribuye a la fuerza, mientras que cuanto más clara fría sea, más contribuye a la perfección a la inteligencia.

En el romancero medieval se constata esa diferencia entre la significación de la sangre masculina frente a la femenina: la sangre del hombre tiene un significado en los sacrificios, como símbolo de linaje, de poder, de valor, mientras que la de la mujer siempre tiene un significado negativo (MacCracken, 2003). Algo semejante sucede en los Libros de Secretos medievales donde se comparan en general los fluidos masculinos con los femeninos: éstos siempre son débiles, mientras que los masculinos son fuertes, robustos; así, el semen grueso da hijos varones, y el semen débil engendrará niñas (Bildhauer, 2005: 70).

En las mujeres, además de la acumulación del esperma, aumentan esos vapores venenosos cuando no emite regularmente el impuro y destructivo flujo menstrual. La mujer se convierte en un "ser acostumbrado a vivir con su propio veneno" (Canet, 1996), que expulsa regularmente, contribuyendo así a su purgación y cura. De modo que la sangre menstrual no sólo resulta peligrosa para quienes están en contacto con las mujeres, sino también para ellas mismas. La acumulación de esta sustancia en la matriz acaba provocando enfermedades ginecológicas como la suffocatio matricis o histeria, 
ya conocida y tratada desde la Antigüedad, o algunas más generales, como pueden ser infecciones oculares contagiosas, debido a que dichos vapores malignos suben hasta la cabeza, infectan todo el organismo.

Las fuentes médicas defienden como el modo más efectivo para provocar la expulsión de esa materia acumulada el coito. No obstante, ello dependerá de los principios ético-religiosos de los distintos autores, donde unos lo recomendarán libremente, entre ellos los Libros de Secretos medievales, frente a quienes defienden que solamente se debe practicar dentro del matrimonio, lo que provoca que las mujeres viudas y jóvenes solteras estuvieran especialmente expuestas a los riesgos provocados por la acumulación de sangre menstrual en la matriz. Estas últimas debían acudir a los servicios de una obstetrix, la matrona, para que les aplicara ungüentos en los genitales con movimientos circulares a fin de permitir la expulsión de la materia nociva (Jacquart, 1989: 182-186). En general, en los casos en los que la mujer tenga algún desarreglo en su emisión, dichos humores corrompidos degeneran en un veneno muy potente, causante de graves trastornos, e incluso de su propia muerte.

\section{- Menstruación y otras ideaciones}

Lo dicho anteriormente nos lleva a plantear la cuestión de la menopausia como foco de imaginarios sociales. Ello tiene importancia, sobre todo, cuando desaparecen sus emisiones mensuales. Dicha materia queda encerrada en el organismo, contaminando todo su cuerpo, pudiendo incluso envenenar a los que la rodean. Aparte de las dolencias y enfermedades que sufrían, las mujeres cuando alcanzaban la menopausia quedaban relegadas de la sociedad, no eran útiles ya, puesto que su función en la sociedad era procrear y ya no podían (Livi: 1984). Estos aspectos han tenido impacto social a través de una serie de ideaciones colectivamente asentidas. Algunos ejemplos de ello los tenemos en los siguientes ejemplos:

A partir de esta concentración de los vapores en el organismo, se explica el manido tema del mal de ojo, que encontramos ya debatido como un hecho real, sin atisbo de esoterismo o prácticas mágicas en los propios autores clásicos, que le dan una explicación fisiológica. Plinio defiende que la mujer menstruante es capaz de "enturbiar los espejos con sola su mirada", tanto que la compara muchas veces con el Basilisco, ese animal maravilloso que mataba con su mirada. Ese veneno se transmitía por el aire y atacaba de una manera más fuerte a los niños recién nacidos, más frágiles. Resulta evidente que el occidente medieval aprovechará este fundamento físico de un encantamiento como el mal de ojo para asimilar, capturar y condenar a muchas mujeres por la práctica de la brujería, y estas ideas permanecerán hasta el Renacimiento (Jacquart y Thomasset, 1989; Pérez Ibáñez, 2003 y Green, 2005).

Otra creencia popular bastante extendida, llegando incluso a nuestros días, es la relación del ciclo de la menstruación con el agua. Esa preocupación por evitar el baño durante los días del ciclo ya está mencionada como una prohibición expresa, o al menos un consejo médico, en Sorano de Éfeso, mientras que en la menopausia recomienda el baño diario. La influencia nociva de la sangre menstrual sobre el agua llega a exagerarse hasta el punto de derretir el betún asfáltico, como hemos visto 
anteriormente que relataba Plinio (Bildhauer, 2005).

El flujo menstrual puede ser nefasto si interviene en el momento de la concepción debido a ese carácter nocivo que hemos visto. Era una creencia común en la época que los niños concebidos durante la menstruación podían desarrollar fácilmente enfermedades tan terribles y tan socialmente excluyentes como la epilepsia o, sobre todo, la lepra (Jacquart y Thomasset, 1989; Canet, 1996 y Green, 2005).

En otros casos, la ausencia de menstruación en la menopausia generará el nacimiento de pelos en la barba de las mujeres, y así se explicaba el mito de la mujer barbuda. La barba caracteriza al hombre, que es cálido y seco, frente a la mujer que es fría y húmeda. A los hombres lo superfluo se le transforma en barba y en superabundancia de pelo, y será ésta la causa de su aparición en la mujer que ha dejado de menstruar. Como bien exponen Peñalba (1999) y Libis (2001), en cultural antiguas el mito del andrógino -representado por esta visión imaginaria de la mujer- tenía una clara significación positiva. Ahora bien, en nuestro trabajo, como ya hemos expuesto, nos interesa especialmente la creación de construcción imaginaria social en la estructura cultural cristiana, de ahí que no nos ocuparemos de estas cuestiones.

\subsection{ANÁLISIS SOCIO-HERMENÉUTICO}

En otros casos, la ausencia de menstruación en la menopausia generará el nacimiento de pelos en la barba de las mujeres, y así se explicaba el mito de la mujer barbuda. La barba caracteriza al hombre, que es cálido y seco, frente a la mujer que es fría y húmeda. A los hombres lo superfluo se le transforma en barba y en superabundancia de pelo, y será ésta la causa de su aparición en la mujer que ha dejado de menstruar. Como bien exponen Peñalba (1999) y Libis (2001), en cultural antiguas el mito del andrógino -representado por esta visión imaginaria de la mujer- tenía una clara significación positiva. Ahora bien, en nuestro trabajo, como ya hemos expuesto, nos interesa especialmente la creación de construcción imaginaria social en la estructura cultural cristiana, de ahí que no nos ocuparemos de estas cuestiones.

En los apartados anteriores hemos visto algunos ejemplos de los elementos ficcionales que han traído consigo los actuales imaginarios sociales relativos a la menstruación en el contexto histórico greco-romano y medieval. A partir de aquí será posible hacer un análisis socio-hermenéutico de los imaginarios sociales que subyacen a dichos elementos socio-históricos.

Este marco imaginario transmite socialmente unas características que, en función de unos determinados intereses, se va haciendo relevantes a través de la comunicación de las mismas. Por el contrario, existen unas características subterráneas que, en función de los mismos intereses que se mantendrán en una zona social opaca, sombría. Esta idea de las características subterráneas se puede identificar con la idea de la invisibilidad social. De hecho, en los ejemplos expuestos hemos comprobado como la mujer era mostrada como un sujeto malo, como un varón imperfecto, como un ser casi demoníaco. Dicho de otro modo, la mujer será la expresión humana de lo inacabado, de lo erróneo. En cambio, el varón es el ideal, lo adecuado, lo ejemplificante. 
Esta estructura imaginaria se materializa en los tratados médicos ginecológicos. En el siglo XVIII, entusiasmo de la ilustración por la naturaleza y la idea de construir la sociedad con arreglo a las leyes de esta, hizo que se diera voz preponderante a los médicos a la hora de entender la naturaleza humana. La confianza en la imparcialidad y objetividad de la ciencia hacía pensar en que ésta podría decidir en el debate sobre el carácter intelectual y físico de las mujeres. Para poder excluir a las mujeres de la esfera pública, será necesario demostrar una "diferencia natural" entre hombres y mujeres, para así legitimar la exclusión (Schiebingen, 1991: 309-310). Así, surge en esa época la teoría de la complementariedad, según la cual hombres y mujeres no son iguales ni en lo físico ni en lo moral (psicológico), sino opuestos complementarios y la ciencia -los médicos- se decantaron plenamente por esta teoría, dotándola de legitimidad científica. A partir de entonces, las mujeres no serían sólo consideradas inferiores al hombre, si no diferentes de ellos y por tanto no comparables (Schiebingen, 1991: 311).

Las diferencias basadas en el calor corporal fueron reemplazadas por la teoría de las dos esferas, según la cual los hombres pertenecían a la esfera pública, ganaban el salario fuera de la casa y las mujeres (excepto en el caso de las clases inferiores o trabajadoras) eran esposas y madres en la esfera doméstica de lo privado. A finales del siglo XIX comenzaron a aparecer nuevas metáforas que planteaban diferencias fundamentales entre los sexos. Un biólogo del siglo XIX, Patrick Geddes, percibía dos tipos de supuestos procesos en el nivel celular: "procesos sintéticos, constructivos", llamado 'anabolismo' y "una serie descendente, perjudicial de cambios químicos" denominado katabolismo (Martin, 1987: 32). La relación entre ambos se describía en términos abiertamente económicos:

"los procesos de ingresos y gastos deben estar equilibrados, y los gastos no deben en su conjunto superar a los ingresos o bien capital de la célula de la materia viva se perderá, un hecho que a veces no se evita de manera exitosa... Del mismo modo que los gastos y los ingresos deben equilibrarse al final del año, pero pueden diferir enormemente en momentos concretos, así sucede con la célula del cuerpo. Los ingresos también pueden continuamente preponderar y aumentamos en salud, o de forma similar en peso, o en anabolismo. A la inversa puede predominar el gasto, pero el negocio puede proseguir con pérdidas; y de manera similar podemos vivir durante un una temporada perdiendo peso o katabolismo. Este juego perdedor de la vida es lo que denominamos un hábito Katabolico. En la especie humana, así como en casi todos los animales superiores, las hembras eran predominantemente anabólicas y los machos katabólicos. Aunque los términos de esta metáfora de gasto y ahorro no está del todo claro si el katabolismo es un activo o valor, cuando presenta las diferencias masculino y al femenino no queda ninguna deuda de lo que él considera preferible: "por lo general es cierto que los machos son más activos, enérgicos, entusiastas, apasionados y variables; las hembras más pasivas, conservadoras, perezosas y estables... los machos más activos, con un mayor rango de experiencias por tanto, pueden tener cerebros más grandes y más inteligencia; pero las hembras especialmente como madres, tienen indudablemente una parte mayor y más habitual de emociones altruistas. Los machos son usualmente más fuertes tienen mayor independencia y coraje; las hembras superan en constancia de afecto y simpatía” (Martin, 1987: 33). 
A pesar de que hay diversidad de modos en que se pueden relacionar las metáforas de gasto-ahorro con el género, es claro que, en este caso es abiertamente denigrante, como hace Geddes y denigra las funciones que por primera vez se ven cómo su solamente femeninas sin analogía en los machos. Como ha señalado Emily Martin (1987, 1991), las metáforas elegidas para describir la ovulación y la espermatogénesis son de tal tipo que, aunque en un principio pudieran concebirse ambos procesos como análogos o semejantes, se presentan como dos procedimientos dicotómicos en los que el primero recibe una valoración negativa frente a la positiva del segundo.

Así, en primer lugar, se describe el ciclo menstrual como un fracaso, dado que el objetivo del ciclo es producir óvulos que puedan ser fecundados, a la vez que preparar un lugar adecuado para el desarrollo del embrión. La menstruación, entonces, será signo evidente de que lo anterior y, al no haberse producido la fecundación, adquiere un carácter destructivo. De ahí que la menstruación son los "restos del recubrimiento uterino" que se expulsa dado que no hay embarazo en marcha, es el resultado de la "necrosis o muerte del tejido uterino".

En cambio, los textos médicos presentan la creación de millones de espermatozoides, "hasta doscientos millones cada veinticuatro horas"1. (Rayner, 1985, pág. 74). Esa producción de esperma es continua, de la pubertad a la vejez. Por el contrario, la producción de óvulos está determinada al nacer: en el momento de su nacimiento, los ovarios de una niña contienen entre cuarenta mil y trescientos mil óvulos, “de los cuales sólo llegará a evacuar un máximo de quinientos” (ibidem, pág. 73). La ovulación se convierte, a nivel de la significación textual, como algo doblemente negativo: los óvulos que no se ‘evacúan' degeneran, convirtiéndose en un despilfarro; pero, además, "la formación de óvulos es un proceso de maduración más que de elaboración” (ibidem, pág. 75), frente a la creación de los espermatozoides. En Mountcastle (1980), la afirmación es semejante: "mientras la mujer se desprende de un solo gameto cada mes, los tubos seminíferos producen millones de espermatozoides cada día”.

En el mismo sentido se pronuncia el texto estándar Biology of the Cell, escrito por Alberts et al., donde se afirma que la ovogénesis es un desperdicio. De 7.000.000 de células germinales ováricas existentes en el embrión femenino, la mayoría degenera en el ovario, de modo que al nacer sólo hay entre 40.000 y 300.000 . Y dice más adelante: "Durante los cuarenta años aproximados de vida reproductiva, sólo se liberan unos 400-500 óvulos... los demás habrán degenerado. Todavía es un misterio por qué se forman tantos óvulos sólo para que perezcan en el ovario”. Es decir, no tiene sentido formar algo que no se va a utilizar, se está produciendo un desperdicio de óvulos. Sin embargo, no se hace semejante pregunta, ni valoración, con respeto a los millones de espermatozoides 'producidos' diariamente por los varones para que uno sólo pueda unirse al óvulo.

Para que haya desperdicio o despilfarro, tiene que haber exceso. Pero hagamos unos pequeños cálculos. Supongamos que una mujer 'libere’ 500 óvulos a lo largo de

\footnotetext{
${ }^{1}$ En todas estas citas, el énfasis añadido es nuestro.
} 
su vida reproductiva y que tenga 2-3 hijos. Eso supondría una inversión de unos 250170 óvulos por hijo. Ahora bien, supongamos el mismo número de hijos en la vida reproductiva de un varón. Si produce 200.000 .000 de espermatozoides diarios, a lo largo de 40 años (supongamos que está activo hasta los 55 años, aunque sabemos que, aunque la producción de espermatozoides disminuye con la edad), habrá producido 73.000.000.000 de espermatozoides al año, unos 2.920.000.000.000 en toda su vida. Es decir, ¡habrá utilizado entre 1.460.000.000.000 y 973.000.000.000 de espermatozoides por hijo!

En la metáfora utilizada en los libros mencionados, se señala de forma significativa que la mujer sólo produce un óvulo, mientras el varón produce millones de espermatozoides; pero podría utilizarse una metáfora alternativa en la que se señalaría la regularidad con que se producen los óvulos y, por tanto, su mayor posibilidad de ser fecundado, mientras se requieren millones de espermatozoides para fecundar un solo óvulo. Así, la metáfora del despilfarro, glorifica la cantidad, aunque se puede oponer la de la eficacia, la fiabilidad o regularidad (Herschberger, 1948, Tomlinson, 1995), invirtiéndose así el significado y considerando que la producción de enormes cantidades de espermatozoides es un gasto, un error. La primera metáfora idealiza los números; la segunda, la eficacia y la regularidad, invirtiendo la imagen del gasto tan usual en las explicaciones de los procesos fisiológicos y socio-evolutivos femeninos (Pérez Sedeño, 2008).

Si la menstruación era concebida textualmente como patológica, la menopausia no se quedaba atrás. Dicho proceso natural se consideraba que al no tener un análogo en los hombres (según muchas explicaciones médicas del siglo XIX) la mostrabas textualmente como una crisis que era probable que produjera un aumento de la enfermedad. De hecho, la metáfora del cuerpo como un pequeño negocio (tal y como vimos antes) también se aplicaba la menopausia. Hay una explicación de finales del siglo XIX que argumentaba de forma específica contra el modelo del ajuste de Tilt: "cuando el período de productividad termina la actividad de los tejidos ha alcanzado su culminación, el poder de secretar de los órganos glandulares comienza a disminuir, el epitelio se hace menos sensible y menos susceptible a influencias infecciosas y se produce la atrofia y la degeneración de los procesos activos de construcción (Currier, 1897, 25-26; citado en Martín 1987, 35). La menopausia es, entonces, una pérdida o, si se prefiere, una degeneración. Pero esto no es el caso que nos ocupa.

La menstruación, entonces, no sólo lleva la connotación de un sistema productivo que ha dejado de producir, también lleva la idea de que la producción ha fracasado. Por tanto, es un fenómeno de generación de desperdicios, sobras, etcétera. Quizás una razón de tener una imagen negativa del fallo de producción que se asocia la menstruación es precisamente que las mujeres están, en algún sentido siniestro, fuera de control cuando menstruar.

Todo ello parece conformar la textualidad de un ser centrado en el proceso reproductivo y continuador de la especie. Además, también muestra que la mujer será completa cuando es capaz de proporcionar un útero caliente que pueda nutrir el esperma del macho. De esta manera, lógicamente, su finalidad será la de tener hijos y cuidarlos en casa. Nos resulta evidente el considerable poder negativo que hay detrás 
de la significación del fracaso de la (re)producción cuando se aplica de forma metafórica a los cuerpos de las mujeres. Vern Bullough comenta optimistamente que "ningún científico reputado consideraría hoy en día la menstruación es algo patológico", pero este párrafo extraído de un libro de texto reciente desmiente esa esperanza:

"si no se produce fertilización y embarazo, el corpus luteum degenera en los niveles de estrógenos y progesterona decae. Según los niveles de estas hormonas disminuye y se retira sus efectos estimuladores, los vasos sanguíneos del endometrio padecen espasmos prolongados (contracciones) se reduce el flujo de sangre en el área del endometrio alimentada por los vasos. La alta resultante de sangre hace que degeneren los tejidos de la región afectada. Después de un tiempo, los vasos se relajan, lo que permite que la sangre fluya por ellos de nuevo. Sin embargo, los capilares del área se han hecho tan débiles que la sangre gotea por ellos. Esta sangre y el tejido endometrial deteriorado se descargan desde el útero como flujo menstrual. Según comienza un nuevo ciclo ovárico y aumenta el nivel de estrógenos, la capa funcional del endometrio se repara y de nuevo comienza a proliferar”. (citado en Martin, 1987: 47).

¿Cuál es el lenguaje en el que se describe la menopausia? En la menopausia, según un libro de texto, los ovarios "no responden" a la estimulación de las gonadotropinas, a las que solían responder. Como resultado los ovarios "retroceden". Al final del ciclo, el hipotálamo se ha hecho "adicto" al estrógeno por todos esos años de menstruación. Como resultado de la "retirada" de estrógenos en la menopausia, el hipotálamo comienza a dar “órdenes inadecuadas”. Dicha expresión (“órdenes inadecuadas”) es una explicación más popular que científica, ahora bien se incluye, así, en algunos de estos textos. Sigamos, "la glándula pituitaria durante el cambio de vida comienza a perturbarse cuando los ovarios no responden a sus secreciones lo cual tiende a afectar su control sobre otras glándulas. Eso produce un desequilibrio temporal existente entre todas las glándulas endocrinas del cuerpo, lo cual podría muy bien llevar a perturbaciones que podrían implicar al sistema nervioso de una persona”. Comprobamos, entonces, como los elementos imaginarios se mantienen en los textos científicos que tienen más actualidad.

¿Por qué esta oposición negativo/positivo? ¿Por qué no considerar la fisiología reproductiva femenina de una manera positiva? Desde luego, el componente cultural del conocimiento al que contribuyen las metáforas es clave. Obsérvese que las metáforas empleadas corresponden a estereotipos culturales de lo masculino y lo femenino en occidente. Son estereotipos que toman una forma dicotómica y jerárquica, en donde lo femenino se asocia con la pasividad, la fragilidad, la irracionalidad, la subjetividad, etc., y lo masculino con la actividad, la fuerza, la racionalidad, la objetividad (Pérez Sedeño, 2008). Ello implica que estos elementos ficcionales se localizan en el núcleo de la estructura de la ciencia. De hecho, estos imaginarios, evidentemente transformados, han permanecido de un modo u otro hasta la actualidad y ha terminado conformando parte de la estructura de la ciencia.

No obstante, Pérez Sedeño (2001) nos dice que el sujeto ideal de razón y de objetividad pura, que ha sido uno de los pilares fundamentales de la ciencia y de la 
epistemología moderna, sólo ha sido cuestionado muy recientemente. (Pérez Sedeño, 2001: 294). A este respecto podemos añadir que en el momento histórico que hemos analizado previamente se conforma sustancialmente este sujeto ideal a raíz de una negación de todo lo femenino, incluso de lo más interno y propio de ella fisiológicamente. En este sentido, en los textos se nos muestra un conocimiento científico descontextualizado en la que las características de la mujer se generalizan, no se establece ningún tipo de variabilidad y no se hace mención del contexto sociohistórico. Esta es la razón de que en la actualidad se esté produciendo un cuestionamiento de la ciencia, denominada androcéntrica, desarrollando la idea de un conocimiento científico contextualizado.

"Es decir, se entiende que el conocimiento científico es, sobre todo, una práctica que tiene lugar en un contexto determinado y es evaluado respecto a fines particulares: es decir, se considera la ciencia como proceso y actividad de comunidades científicas insertas en contextos sociohistóricos concretos en cuyo seno encontramos valores personales, sociales y culturales, preferencias de grupos $\mathrm{o}$ individuales, de tipo cultural, social, que inciden en diversos modos y grados 0 que pueden incidir sobre la práctica científica” (Pérez Sedeño, 2001: 294).

Dicho de otro modo, la ciencia termina por ser configurada en base al ideal masculino que, tal y como hemos visto a la hora de hablar del coito, logra solventar los problemas inherentes a la mujer. Este imaginario acaba transformándose en un imaginario relativo a la percepción de la realidad. Si la mujer es imperfecta, tal y como nos lo muestra su propia naturaleza imperfecta y venenosa, el conocimiento que ella pueda desarrollar de la realidad será también erróneo, equivocado e, incluso, perjudicial. De ahí que el sujeto cognoscente propio de toda la historia del conocimiento científico humano sea un varón. Asimismo, dicho sujeto cognoscente presentará los valores del varón y tenderá a eliminar los valores propios del rol femenino.

Buena parte de esta concepción imaginaria es dependiente de los elementos imaginarios negativos a los que se le ha sometido a la mujer por el varón. Este imaginario ha permanecido tanto y con variaciones moderadas que ello nos permite afirmar la existencia de un discurso de lo imaginario social tautológico referido a la mujer como ser perjudicial e imperfecto. Este imaginario social tautológico, tal y como nos dicen Castro Nogueira y colaboradores (2008), es uno de los extremos de cualquier imaginario social y se organiza como una secreta axiomática de cualquier cultura. A partir de él, se irá dictando lo posible y lo imposible, lo pensable y lo no pensable, así como lo visible y lo invisible.

En este sentido podemos entender cómo, a día de hoy, todavía se mantiene incólume el imaginario de la ciencia como actividad descubridora de una Verdad desarrollada por unas determinadas personas (varones), como expresión máxima de la Razón de los hombres y como garante del progreso social. Este imaginario científico, que podría calificarse además de ilustrado, como greco-romano, es la base de la construcción de la actividad científica androcentrada. Ella estará asociada con lo universal, la cultura, la objetividad, la racionalidad y lo público, en cambio lo particular, la naturaleza, la subjetividad, lo irracional y lo privado ha sido relegado de 
ella, al tiempo que se identificaba con lo femenino (Echeverría, 1999).

\section{CONCLUSIÓN}

Para terminar podemos decir que los imaginarios sociales presentes en las creencias populares y en algunas tradiciones son tan fuertes que llegan a condicionar los estudios científicos e incluso en la propia ciencia, como hemos podido comprobar. Pero, además, también son capaces de influir en todos los aspectos de la sociedad no solamente antigua, sino hasta llegar al Renacimiento.

Para completar la visión de la mujer venenosa en la antigüedad necesitaríamos conocer cómo se consideraban ellas mismas, cómo explicaban todos estos fenómenos que se incluyen entre las prácticas mágicas. Lamentablemente, debido a esa desconsideración social de la que es objeto la mujer greco-romana, no tenemos más que los testimonios masculinos referidos a ellas, por lo que tendremos que conformarnos con la idea de una mujer con poderes maravillosos que la permitían, en cierto modo, intervenir en el curso de esa sociedad que se empeña en relegarla a un papel secundario.

Resulta más fácil ver cómo nuestras ideas científicas del pasado, que ahora nos parecen erróneas o simples, están imbuidas de supuestos culturales que en las actuales. Estos estereotipos y creencias de género tienen un gran poder y función en nuestra cultura. Las atribuciones de género (y los estereotipos y sesgos sexistas asociados) son consistentes con las ideas y concepciones del mundo de las personas que crean conocimiento científico. Estas mismas personas las incluyen en el conocimiento que generan, contribuyendo de este modo a incorporarlas como 'hechos científicos' con la carga de autoridad que eso conlleva. Así, las metáforas que usan los biólogos para describir sus datos tienen importantes consecuencias no sólo cognitivas, sino sociales, que a veces quedan ocultas porque están tan arraigadas que parecen obvias. Porque uno de los factores que hace aceptable las metáforas en ciencia es su aparente falta de arbitrariedad.

Las metáforas proporcionan una forma de pensar sobre el campo de estudio, sobre los objetos o componentes que interactúan, que, una vez 'visualizado' o 'pensado' se convierte en nuevas formas de conocimiento que, a su vez, puede resultar en una nueva forma de control social que se puede ejercer sobre los componentes del campo. Unas metáforas son mejores que otras, se aceptan con mayor facilidad y oponen una gran resistencia a ser removidas o eliminadas del lenguaje científico porque revelan de una forma muy clara un conocimiento social compartido. La efectividad de las metáforas depende de las convenciones sociales compartidas, de los parecidos de familia ya vigentes y, seguramente de manera primordial, de la autoridad que, por convención, se otorga a quienes las usan. Las metáforas que en algún momento fueron socialmente eficaces, pueden dejar de serlo gracias, en parte, a los cambios en la ideología de género.

Nuestro análisis hermenéutico ha mostrado una serie de elementos que se han ido haciendo relevantes en el proceso de configuración de la significación social de la 
mujer. En cambio, dejan en la opacidad, en la sombra, otros elementos hermenéuticos que no hemos analizado en esta ocasión. A nuestro juicio, la medicina actual todavía mantiene alguno de los procesos de textualidad en los que la mujer sigue siendo considerada de un modo negativo. Por ello es conveniente seguir investigando estos elementos para poder realizar una deconstrucción de los mismos y reconstruir la significación de la fisiología femenina desde otra perspectiva.

La crítica de esas y otras metáforas puede mostrar cómo los científicos usan a menudo metáforas pobres debido a que compromisos no explícitos o supuestos sexistas, con jerarquías de género o de otro tipo, deforman su juicio de un modo que no pueden ver. Cierto tipo de metáforas, como algunas aquí señaladas, puede cambiar el régimen de verdad relegando a ciertos grupos a un estatuto de inferioridad. Eliminarlo es muy difícil y exige análisis y prácticas muy sutiles, como pueda ser el desenmascaramiento de esas metáforas que ayudan a mantener la configuración genéricamente sesgada de la sociedad.

\section{REFERENCIAS BIBLIOGRÁFICAS}

ARISTÓTELES (2010): Obra biológica (De Partibus Animalium, Motu Animalium, De Incessu Animalium), trad. Rosana Bartolomé. Madrid: Luarna ediciones, S.L.

AUBER, EDOUARD (1841): Hygiéne des femmes nerveuses ou conseils aux femmes pour les époques critiques de leur vie. Paris: Baillière.

BAEZA, MANUEL A. (2008): Mundo real, mundo imaginário social. Teoría y práctica de sociología profunda. Concepción: Universidad de Concepción.

BERNIS, CARMEN y CÁMARA, CRISTINA (1982): La mujer en la constitución histórica de la Medicina, en: Durán, M.A. (Ed.) Liberación y Utopía (pp.205231). Madrid: Akal.

BILDHAUER, B. (2005): The Secrets of Women (c. 1300): A Medieval Perspective on Menstruation, en: Shail, A., Howie, G., Menstruation. A cultural history (pp.65-75). New York: MacMillan.

CAMACHO, JORGE LUIS (2001): Los límites de la transgresión: la virilización de la mujer y la feminización del poeta en José Martí, Revista Iberoamericana, 194195, 69-78.

CANET, JOSÉ LUIS (1996): La mujer venenosa en la época medieval, Lemir. Revista de Literatura Española Medieval y del Renacimiento, 1. http://parnaseo.uv.es/Lemir/Revista/Revista1/Mujer_venenosa.html).

CAPPAI, CHIARA DE FILIPPIS (1993): Medici e medicina in Roma antica. Turin: Terrenia Stampatori. 
CARRETERO, ENRIQUE (2011): Imaginario e identidades sociales. Los escenarios de actuación del «Imaginario social» como configurador de vínculo comunitario, en: Coca, J.R; Valero, J.; Randazzo, F. y Pintos, J.L. (Coords.) Nuevas posibilidades de los imaginarios sociales (pp. 99-112). Santa Uxía de Riveira (A Coruña, España): Ceasga.

CAZARÍN, ANGÉLICA (2011-12): Género y poder. La masculinización de las mujeres en la política mexicana. Revista Mexicana de Estudios Electorales, 11, 13-27.

CASTORIADIS, CORNELIUS (1983): La institución imaginaria de la sociedad. Barcelona: Tusquets.

CASTRO NOGUEIRA, LUIS; CASTRO NOGUEIRA, MIGUEL A. Y MORALES NAVARRO, JULIÁN (2008): Metodología de las ciencias sociales. Madrid: Tecnos.

COCA, JUAN R. (2010): La comprensión de la tecnociencia. Huelva (España): Hergué.

COCA, JUAN R. (2015): Propuesta de una nueva conceptualización de los imaginarios sociales, en: Narváez, A. B.; Vázquez, G. y Fitch, J. M. (Coords) Lo imaginario. Seis aproximaciones (pp. 113-127). Nuevo León (México): UANL/Université Lille/Tilde Editories.

DURAND, GILBERT (1981): Las estructuras antropológicas de lo imaginario. Introducción a la arquetipología general. Madrid: FCE.

ECHEVERRÍA, JAVIER (1999): Introducción a la metodología de la ciencia. La filosofía de la ciencia en el siglo XX. Madrid: Cátedra.

ELLIOT, DYAN (1999). Fallen Bodies: Pollution, Sexuality and Demonology in the Middle Ages. Philadelphia: University of Pennsylvania Press.

FERNÁNDEZ TIJERO, M ${ }^{\mathrm{a}}$ CARMEN (2009): Mujeres médicas en la antigua Roma: de la marginación al reconocimiento, en: Rosa, C. (Coord.). Innovación educativa e historia de las relaciones de género (pp. 75-90). Valladolid: Universidad de Valladolid.

GIROLA, LIDIA (2012): Representaciones e imaginarios sociales. Tendencias recientes en la investigación, En: Garza Toledo, E. de la y Leiva, G. (Eds.) Tratado de metodología de las ciencias sociales: perspectivas actuales (p.441468). México: UAM/FCE

GOUREVITCH, DANIELLE (1984): Le mal d'etre femme. La femme et la médecine dans la Rome Antique. Paris: Les Belles Lettres. 
GREEN, MONICA H. (2005): Flowers, Poison and Men: Menstruation in Medieval Western Europe, en: Shail, A. \& Howie, G. (Eds.), Menstruation. A Cultural History (pp. 51-64). Basingstoke: Palgrave McMillan.

IGLESIAS, PILAR (2003): Mujer y Salud: las Escuelas de Medicina de Mujeres de Londres y Edimburgo. Tesis Doctoral, Málaga: Universidad de Málaga.

JACQUART, DANIELLE, THOMASSET, CLAUDE (1989). Sexualidad y saber médico en la Edad Media, Barcelona: Labor.

LIBIS, JEAN (2001): El mito del andrógino. Madrid: Siluela.

LIVI, JOCELYNE (1984): Vapeurs de femmes: essai historique sur quelques fantasmes médicaux et philosophiques. Dijon: Collection du Studiola, Navarin.

LLOYD, GEOFFREY ERNEST RICHARD (1983): Science Folklore and Ideology. Cambridge: Cambridge University Press.

MCCRACKEN, PEGGY (2003): The Curse of Eve, the Wound of the Hero: Blood, Gender and Medieval Literature. Philadelphia: University of Michigan.

MARTIN, EMILY (1987): The Woman in the Body: A Cultural Analysis of Reproduction. Boston: Beacon Press.

MARTIN, EMILY (1991): "The Egg and the Sperm: How Science Has Constructed a Romance Based on Stereotypical Male-Female Roles”, Signs, 16/3, 485-501.

PARÍS-HUESCA, EVA (2013): Masculinización y virilización de la escritura de la mujer de vanguardia: el caso de Estación. Ida y Vuelta y El Personaje Presentido, Entrehojas: Revista de Estudios Hispánicos, 3/1, Article 4. Accesible en: http://ir.lib.uwo.ca/entrehojas/vol3/iss1/4.

PEÑALBA, MERCEDES (1999): El mito de andrógino o la búsqueda de la unidad perdida. En "Les Météores" de Michel Tournie", VII Coloquio APFUE (Asociación de Profesores de Francés de la Universidad Española), Cádiz: Universidad de Cádiz, 2, pp. 195-204

PÉREZ IBÁÑEZ, MARÍA JESUS (2003): "Las mujeres y la enfermedad en el Renacimiento castellano”. En: Rosa, C.; Sto. Tomás, M.; Del Val, M. I. y Dueñas, M. J. (Coords.), La voz del olvido: mujeres en la historia, 141-161, Valladolid: Universidad de Valladolid.

PÉREZ SEDEÑO, EULALIA (2001): La perspectiva de género en ciencia y tecnología: innovación y nueva caracterización de las disciplinas. En: López Cerezo, J. A. y Sánchez Ron, J. M. (Eds.), Ciencia, Tecnología, Sociedad y Cultura en el cambio de siglo (pp. 283-296). Madrid: Biblioteca Nueva-OEI. 
PÉREZ SEDEÑO, EULALIA (2008): Mitos, creencias, valores: cómo hacer más «científica» la ciencia; cómo hacer la «realidad» más real, Isegoría, 38, ene-jun, 77-100.

PINTOS, JUAN-LUIS (2014): Algunas precisiones sobre el concepto de imaginarios sociales. Revista Latina de Sociología, 4, 1-11.

PLATÓN (1992): Diálogos, VI. Filebo; Timeo; Critias, Madrid: Gredos.

PLINIO (2002): Historia natural. Madrid: Cátedra edición de Josefa Cantó [et al.]

SCHIEBINGER, LONDA (1991): The Mind Has No Sex? Women in the Origins of Modern Science. Harvard University Press: Cambridge.

SIMMEL, GEORG (2000): La trascendencia de la vida, Reis, 89, 297-313.

VV.AA. (1984): Nueva Biblia Española, Madrid: Ediciones Cristiandad. 